$$
2 .
$$

Derecho maritimo 

Revista de Derecho

de la Pontificia Universidad Católica de Valparaíso XXIX (Valparaíso, Chile, $2^{\text {do }}$ Semestre de 2007)

[pp. 143 - 167]

\title{
¿SUBSISTE LA FORTUNA DE MAR EN EL DERECHO MARÍTIMO CHILENO?
}

[Does Naval Property Still Remain in the Chilean Maritime Law?]

\author{
Claudio Barroilhet Acevedo* \\ Pontificia Universidad Católica de Valparaíso
}

\begin{abstract}
RESUMEN
La fortuna de mar es una institución muy antigua del Derecho marítimo, propia de los sistemas legales civilistas, que consiste en considerar a cada nave como un patrimonio especial y separado de los restantes bienes que su propietario o armador mantenga en tierra, y aún del resto de su flota. La consecuencia de esta separación es que las deudas que surjan al explotar una nave sólo pueden hacerse efectivas en la misma nave y no en los restantes bienes de su propietario o armador. Este artículo analiza si esta figura existe en nuestro derecho marítimo y cuáles son sus contornos.

Palabras clave: Fortuna de mar - Patrimonio naval - Patrimonio de afectación - Teoría de la personificación de la nave - Universalidad de hecho - Universalidad de derecho - Privilegio marítimo - Crédito privilegiado - Limitación de responsabilidad - Fondo de limitación de responsabilidad.
\end{abstract}

\begin{abstract}
Naval property is a very old institution of Maritime Law, inherent of the civil legal systems, consisting in considering each vessel as a special and separate patrimony of the other property that their owner keeps on land and even from the rest of his fleet. This separation results in that the debts arising from trading a vessel can only be effective in the vessel and not in the other property of their owner. This article analyses if this aspect is present in our maritime law and which is its profile.

KeYwords: Navy property - Naval Patrimony? - Assigned patrimony - Theory of personification of vessels - Group of property formed by the will of the owner and divisible by such owner - Group of property created by law and only divisible as permitted legally - Maritime lien - Privileged credit - Limitation of liability - Fund of limitation of liability.
\end{abstract}

* Profesor de Derecho Marítimo de la Facultad de Derecho de la Pontificia Universidad Católica de Valparaíso. Dirección postal: Avda. Brasil 2950, Valparaíso, Chile. Correo electrónico: cbarroilhet@csav.com 


\section{INTRODUCCIÓN}

La fortuna de mar o patrimonio naval es una noción antiquísima en el derecho marítimo, consistente en que el dueño de la nave, o el naviero, que hace una embarcación a la mar con fines de explotación comercial, jurídicamente erige una masa de activos y pasivos independientes a los bienes que posee en tierra, cuyo principal componente es la propia nave, y ellos se afectan exclusivamente a la explotación de dicha embarcación, de suerte que las ganancias que se obtengan se destinarán al pago de las deudas que contraiga en los diversos viajes que efectúe, pero las deudas que no puedan pagarse con dichos bienes no podrán perseguirse en contra de los bienes que ese armador o dueño tenga en tierra, que son independientes de su fortuna de mar, aunque su dueño sea una misma persona.

Esta noción ha ido evolucionando a través de la historia, en función de la manera cómo se ha regulado el sistema de créditos y de deudas de la industria naval. Ello, por cuanto existe una estrecha relación entre el patrimonio naval y la limitación de responsabilidad de los sujetos que protagonizan el negocio naviero, al punto que la fortuna de mar ha sido el vehículo jurídico a través del cual se ha organizado y operado la institución de la limitación de responsabilidad.

El objetivo de este artículo es determinar en qué medida la fortuna de mar subsiste en nuestro actual ordenamiento jurídico marítimo e identificar los rasgos que presenta. No pretendo analizar in extenso los privilegios marítimos, la limitación de responsabilidad ni otras materias afines del derecho marítimo, sino tangencialmente y sólo en la medida que sea necesario al objetivo antes planteado.

Lo primero que advertimos la iniciar nuestro análisis es que el legislador no estableció a la fortuna de mar como un patrimonio especial de manera explícita y sistemática: no existe un título o párrafo del libro III del Código de Comercio que se dedique únicamente a la fortuna de mar. A priori, no creo que ello sea una razón para descartar, de plano, su existencia.

El análisis circundará en torno, principalmente, al título $3^{\circ}$ del libro III, rubricado De los privilegios y de la hipoteca Naval, materia que los autores titulan como el "crédito naval".

\section{LA FORTUNA DE MAR Y LOS ELEMENTOS DEL ESTATUTO PATRIMONIAL}

Ya me aventuraba a sostener que la fortuna de mar se ha identificado como un patrimonio, de hecho, también se la denomina patrimonio naval. A fin de analizar si ella conforma o no un patrimonio en nuestra actual 
legislación, corresponde indagar acerca de los elementos que definen a un patrimonio.

El estatuto de un patrimonio se conforma con los siguientes aspectos. Primero, es básico que exista una masa de activos (entendiendo por tales cosas corporales e incorporales, según los define el Código Civil) ${ }^{1}$. Para que exista esta masa de activos, es necesario que la ley ${ }^{2}$ establezca la vía a través de la cual ingresan estos bienes a la masa o cómo ellos se afectan al patrimonio. Luego, es peculiar a un estatuto patrimonial que se establezca la forma de administrar y de disponer de los bienes que conforman la masa, lo que nos lleva a la identificación de su titular y la determinación de las facultades que tiene sobre esta masa. Enseguida, debe señalarse qué créditos pueden dirigirse y hacerse efectivos en esa masa patrimonial o, visto desde la óptica del patrimonio, cuáles son las deudas que le gravarán.

Analicemos ahora si estos elementos se presentan, y cómo, en la fortuna de mar.

\section{La masa.}

El artículo 839 del Código de Comercio señala: "Los privilegios establecidos en este título serán preferidos y excluirán a cualquier otro privilegio general o especial regulados por otros cuerpos legales, en cuanto se refieran a los mismos bienes y derechos. Con todo, las normas sobre prelación y privilegios en materia de contaminación o para precaver perjuicios por derrames de substancias dañosas, que se establecen en los convenios internacionales vigentes en Chile y en la Ley de Navegación, gozarán de primacía sobre las disposiciones de este titulo, en las materias especificas a que ellos se refieren. No pueden constituirse prendas, gravámenes, prohibiciones y embargos independientemente sobre partes o pertenencias ya incorporadas a naves o artefactos navales".

La expresión "bienes y derechos" trasunta que el legislador concibió una masa especial, destinada a soportar las deudas que la actividad marítima genera, sólo que la regula desde la perspectiva del crédito (privilegio marítimo) y no como una masa de activos.

¿Cuáles son estos bienes y derechos?

En primer lugar, la nave. Así se desprende de la lectura de ciertas disposiciones.

${ }^{1}$ Artículo 565: "Los bienes consisten en cosas corporales o incorporales. Corporales son las que tienen un ser real y pueden ser percibidas por los sentidos, como una casa, un libro. Incorporales las que consisten en meros derechos, como los créditos, y las servidumbres activas".

${ }^{2}$ Según el artículo 19 N² 4 de la Constitución Política de la República: "sólo la ley puede establecer el modo de adquirir la propiedad, de usar, gozar y disponer de ella y las limitaciones y obligaciones que deriven de su función social". 
El artículo 842 dispone: "Los privilegios de que trata este párrafo, otorgan al acreedor el derecho de perseguir la nave en poder de quien se halle y hacerse pagar con su producto preferentemente a los demás acreedores, según el orden aqui establecido". La norma consagra el derecho de persecución y de realización que detenta el titular de un crédito privilegiado.

El artículo 843 regula la forma de ejercer este derecho: "El titular del privilegio, en ejercicio de su derecho de persecución, podrá solicitar la retención o arraigo de la nave en cualquier lugar donde ella se encuentre, de conformidad con las normas del párrafo 5 del título VIII de este libro".

Para rematar, el artículo 844, señala que "Los siguientes créditos gozan de privilegio sobre la nave, con preferencia a los hipotecarios y en el orden de prelación que se indica [...]" (éstos son los denominados créditos de primera clase), seguido del artículo 846, que establece: "Además, gozan de privilegio sobre la nave, en el orden en que se enumeran, en grado posterior a los indicados en el artículo 844, los siguientes [...]" (créditos de segunda clase). O sea, existen créditos marítimos privilegiados, que pueden hacerse efectivos sobre una nave.

Por su parte, el artículo 858, señala: "Los créditos enumerados en los artículos 844 y 846 que correspondan, gozan de privilegio sobre la nave en construcción desde que ella se encuentre a flote, con la preferencia y rango establecidos en el párrafo precedente", lo que ratifica que la nave es el principal bien que compone la fortuna de mar.

En segundo lugar, el artículo 860 dispone: "Las disposiciones de este párrafo y de los dos precedentes de este título se aplican también a los artefactos navales", lo que coloca a éste como el segundo objeto que conforma una fortuna de mar.

En tercer lugar, y entrando ya a la categoría de las cosas incorporales y, en especial, de los derechos personales o de crédito, el artículo 847 establece: "Los créditos enumerados en los artículos 844 y 846, gozarán también de privilegio sobre los fletes y pasajes correspondientes al viaje en que tengan su origen". La ratio legis estriba en que los fletes y pasajes corresponden a ganancias obtenidas con ocasión de la explotación comercial de una nave, y por tanto estos activos quedan en la misma fortuna de mar.

En cuarto lugar, el artículo 848, preceptúa: "Los privilegios indicados en el artículo 844, se ejercerán también sobre los créditos que se enumeran a continuación, a condición de que se originen en el mismo viaje en que aquéllos se produjeron:/ $1^{\circ}$.- Sobre las indemnizaciones debidas por daños materiales sufridos por la nave y no reparados y sobre las debidas por pérdida de fletes; / $2^{\circ}$.- Sobre contribuciones por daños materiales sufridos por la nave admitidos en avería común y no reparados y sobre las contribuciones debidas por pérdida de fletes, $y / 3^{\circ}$.- Sobre las remuneraciones debidas por auxilios en el mar, 
previa deducción de las cantidades que correspondieren a la dotación de la nave que prestó el servicio".

El precepto en cuestión también coloca como objetos de la fortuna de mar a ciertos créditos o indemnizaciones, como la de los dańos irrogados a la nave y las pérdidas de fletes, que tienen como función sustituir o reemplazar a la nave y al flete como objeto de privilegios, ya que, de no haber existido el daño a aquélla, o de no haberse perdido el flete, el privilegio se habría ejercido en su total extensión sobre su valor.

El número segundo se refiere a una situación similar, pero dentro del contexto de una avería gruesa y el número tercero trata de las remuneraciones por auxilios en el mar, provenientes de un salvamento prestado por la embarcación a otra nave, artefacto naval u objeto, que también se destina a la fortuna de mar, por cuanto se considera como un servicio prestado por la nave con ocasión de su explotación marítima.

Tratándose de estos créditos, el artículo 849 señala: "Los créditos del deudor en contra de terceros de que tratan los dos artículos precedentes, sólo estarán afectos a privilegio mientras dichos créditos estuvieren pendientes de pago, o si las sumas respectivas estuvieren en poder del capitán o del agente del dueño o armador". La justificación de esta norma es doble. Primero, si la deuda se pagó, o se extinguió por otro modo (ya que la norma no restringe su aplicación al pago), la obligación se extinguió, así como su derecho correlativo, por lo que desaparece el activo de la fortuna de mar. $\mathrm{Y}$, segundo, se ha estimado desde antaño que una vez solucionada la deuda, esa ganancia entraba al patrimonio terrestre del armador o dueño de la nave, ya que importaba el retiro de sus utilidades provenientes del ejercicio de la navegación a sus arcas en tierra.

Respecto a la nave y al artefacto naval, hay dos preceptos que merecen ser comentados. Desde luego, el artículo 850, que reza: "Los privilegios sobre la nave podrán hacerse efectivos en las indemnizaciones por seguro de la misma. Sin embargo, cuando se trate de reparaciones efectuadas a la nave, los privilegios establecidos en este párrafo se entenderán de grado posterior al costo de aquéllas para los efectos de recuperarlo del asegurador, si procede. Lo anterior no obsta a que el armador pueda ejercer el derecho de limitación de responsabilidad, de acuerdo con las normas de los párrafos 1 del título IV 4 del titulo $V$ de este Libro. Con excepción de la hipoteca, los privilegios sobre la nave no podrán hacerse efectivos sobre las subvenciones $u$ otros subsidios otorgados por el Estado". También el artículo 840, que señala: "En caso de deterioro, disminución o pérdida del bien sobre el cual recae el privilegio, éste se ejercitará sobre lo que reste, se salve o recupere de aquél, o sobre la indemnización que pague el responsable".

Ambas normas contemplan la subrogación de las indemnizaciones 
que pague (sea un responsable o un asegurador) por pérdida o daño a la nave, y la subsistencia del privilegio sobre lo que reste, salve o recupere del bien objeto del mismo. Así, tales indemnizaciones y restos, también son objeto de la fortuna de mar, las primeras por la vía de la subrogación y el segundo, sencillamente, porque siempre lo fue.

En materia de hipoteca naval, el artículo 876 dispone: "La hipoteca naval comprende el casco, las maquinarias y las pertenencias fijas o movibles de la nave. Comprende también el flete y las subvenciones $u$ otros subsidios otorgados por el Estado, si asi se estipulare. Las partes comprendidas en la nave, no podrán ser objeto de garantías en forma independiente". A continuación, el artículo 877 prescribe: "En caso de pérdida, grave deterioro o innavegabilidad permanente total de la nave o del artefacto naval, el acreedor hipotecario puede ejercer sus derechos sobre lo que reste, se salve o recupere, o sobre su valor de realización, aunque su crédito no hubiere vencido. Salvo que la nave o artefacto naval hubieren sido reparados, el acreedor hipotecario podrá ejercer sus derechos sobre los siguientes créditos de que sea titular el deudor:/ $1^{\circ}$. Indemnizaciones por daños materiales ocasionados a la nave o artefacto naval; $2^{\circ}$. Contribución por avería común por daños materiales sufridos por la nave o artefacto naval; $/ 3^{\circ}$. Indemnizaciones por daños provocados a la nave o artefacto naval con ocasión de servicios prestados en el mar, $y / 4^{\circ}$. Indemnizaciones de seguro por pérdida total o de averías parciales de la nave o del artefacto naval".

Estos preceptos son similares a los que ya comentamos y, su justificación se explica en el concepto de fortuna de mar, por cuanto importan activos de la misma, regulados especialmente con ocasión de la hipoteca naval.

Como apunta Cornejo Fuller, al tratar de los artículos 847, 848 y 850: "todas las situaciones que anteceden suponen lo que se ha llamado 'la fortuna de mar', y de ahí la explicación para que los privilegios se puedan ejercer sobre esos otros valores que reemplazan a la nave misma o que son retribuciones que se deben a la nave, como es el caso de los fletes por pagarse o los premios por servicios de asistencia, siempre que se refieran al mismo viaje"3.

\section{Titularidad de su administración y disposición.}

La disposición más importante en relación a este punto es el artículo 841, que establece: "Las disposiciones de este título también serán aplicables cuando los créditos privilegiados surjan por obligaciones del armador no

\footnotetext{
${ }^{3}$ Cornejo Fuller, Eugenio, Derecho Maritimo Chileno. Explicaciones sobre el libro III del Código de Comercio: De la Navegación y Comercio Marítimos (Valparaíso, 2003), p. 95.
} 
propietario de la nave, salvo que éste disponga de su uso en virtud de un acto ilícito, con conocimiento del acreedor". Según este precepto, el armador que no es propietario de la nave puede gravarla con privilegios.

Pero no sólo el armador que no es propietario puede gravar la nave con privilegios. Evidentemente, y según se desprende del mismo artículo 841, el propietario de la nave puede gravarla con privilegios. En el caso de la hipoteca naval, según el artículo 867: "sólo el propietario podrá hipotecar una nave o artefacto naval".

Luego, si se analizan los créditos privilegiados, podremos inferir que existen otras personas que, sin ser su armador ni su propietario, pueden gravar una nave con privilegios marítimos. En efecto, el artículo 844 número 2 concede un privilegio marítimo a las remuneraciones y demás beneficios que deriven de los contratos de embarco de la dotación de la nave, que según el artículo 102 del Código del Trabajó, puede ser celebrado por el armador, propietario u operador, en calidad de empleadores, lo que me permite sostener que también el operador puede gravar la nave con privilegios.

Enseguida, la misma norma otorga un privilegio a los emolumentos de los prácticos al servicio de la nave. Los prácticos pueden ser contratados por los agentes de la nave, razón que permite afirmar que también éstos pueden afectarla con privilegios marítimos.

Los números 2, 4 y 5 de la norma en comento establecen privilegios marítimos para las indemnizaciones que se adeuden por muerte o lesiones corporales de los dependientes, que sobrevengan en tierra, a bordo o en el agua, y siempre que sean producidas por accidentes que tengan relación directa con la explotación de la nave; los gastos y sacrificios en que hubiere incurrido la autoridad o terceros, para prevenir o minimizar los daños por contaminación o de derrames de hidrocarburos u otras substancias nocivas al medio ambiente o bienes de terceros y las indemnizaciones por daños, pérdidas o averías causados a otras naves, a las obras de los puertos, muelles o vías navegables o a la carga o equipajes, como consecuencia de abordajes u otros accidentes de navegación, cuando la acción respectiva no sea susceptible de fundarse en un contrato, y los perjuicios por lesiones corporales a los pasajeros y dotación de esas otras naves. Estos privilegios marítimos tienen en común que se trata de acciones indemnizatorias que nacen de accidentes. Si estos accidentes los causa la tripulación de la nave, podemos concluir que también ella puede gravarla con privilegios marítimos.

Por su parte, el artículo 846 establece que también gozan de privilegio

${ }^{4}$ Artículo 102: "Es empleador, para los efectos de este párrafo, todo dueño o armador u operador a cualquier título de un buque mercante nacional". 
sobre la nave (aunque en un grado posterior a las hipotecas navales y prendas, y por ello se les denomina privilegios de segunda clase), con el número 1 , a los créditos por el precio de equipamiento de la nave. Por su parte, el artículo 923, que establece las funciones del consignatario de una nave, dispone que éste, por cuenta del dueño, armador o capitán, podrá ( $\left.\mathrm{N}^{\circ} 2\right)$ : "preparar, en cuanto sea necesario, el alistamiento y expedición de la nave, practicando las diligencias pertinentes para proveerla y armarla adecuadamente en todo lo que fuere menester", lo que permite señalar que el agente grava con privilegio a la nave al aprovisionarla y armarla. Lo propio es aplicable al numeral 2, que se refiere a "los créditos por suministros de productos o materiales, indispensables para la explotación o conservación de la nave".

A continuación, el numeral 3 del precepto que nos ocupa, se refiere a "los créditos originados por contratos de pasaje, fletamento o transporte de mercancías". Estos contratos son celebrados por el transportador, fletante y fletador, sean o no el armador de la nave, quienes por esta vía también la afectan con privilegios marítimos.

En fin, el numeral 4 del mismo artículo, trata de los privilegios por desembolsos hechos por el capitán, agentes o terceros, por cuenta del armador, para la explotación de la nave, incluyendo los servicios de agencias, lo que ratifica que estos sujetos también pueden afectar la nave con privilegios marítimos.

En suma, tanto el artículo 841, de manera explícita, como los artículos 844 y 846 , de manera implícita (salvo el $846 \mathrm{~N}^{\circ} 4$ que es explícito), señalan que la nave puede gravarse con privilegios marítimos por una persona que no es su dueño, pero que se encuentra en una relación de explotación con ella. Estas normas regulan la titularidad del patrimonio naval.

Por lo demás, así lo concibió el propio legislador, quien señalaba: "la particularidad del privilegio maritimo, que se refleja de manera especial en el derecho de persecución, ha sido ampliamente reconocido en el proyecto, el cual reafirma la facultad del titular del crédito privilegiado para dirigir su acción contra de la nave misma en que recae el privilegio, sin importar si su tenedor es o no el deudor personal del crédito privilegiado"s.

A mi juicio, ello nos permite afirmar que la fortuna de mar es un patrimonio de afectación, que es independiente a la propiedad de la nave, $y$ que gira en torno a su utilización en la actividad comercial marítima, de suerte que la explotación comercial es un giro o actividad que crea privilegios marítimos que gravan a la fortuna de mar, aunque ella no se lleve a efecto por el dueño de la nave, porque desde el momento que ella entra al

${ }^{5}$ Informe Técnico de la Comisión Redactora del Libro Tercero, de fecha 10 de diciembre de 1985, p. 8. 
negocio marítimo, su propiedad pasa a un segundo plano y su explotación comercial es lo que predomina, aunque ésta no se efectúe por su dueño.

\section{Los pasivos.}

Este aspecto está expresamente regulado en los artículos 844 y 846 , que enumeran los créditos marítimos que gozan de un privilegio sobre la nave y los demás activos que componen la fortuna de mar. Como señalé, no es objeto de este artículo analizar los privilegios marítimos, sino que basta a su propósito señalar que tales pasivos están enumerados en forma expresa y, más aún, los artículos 852 y siguientes regulan el sistema de prelación y preferencia de los privilegios marítimos para su pago.

\section{LA RELACIÓN ENTRE LA FORTUNA DE MAR Y LA LIMITACIÓN DE RESPONSABILIDAD}

\section{Planteamiento.}

Decía que la fortuna de mar ha sido el vehículo jurídico a través del cual se ha organizado y operado la limitación de responsabilidad.

Como señala Ripert al referirse al derecho a limitar responsabilidad del armador, "este principio del derecho marítimo es fundamental. El buque y el flete constituyen para el armador un patrimonio separado que responde de los compromisos relativos a la expedición. Se aparta de la fortuna terrestre esa fortuna de mar, sobre la cual deberían cobrarse los acreedores, en razón de los actos del capitán. Habría que decir aún: las fortunas de mar, pues cada buque constituye una fortuna de mar distinta"6.

Según Fariña, "se forma un conjunto independiente con la llamada 'fortuna de mar', como una universitas rerum autónoma. Esa fortuna de mar aparece así como un patrimonio de afectación o de garantía para determinadas responsabilidades, hallándose integrados por diversos elementos. El flete es uno de ellos, afectado en la misma proporción que el buque"7.

En Chile, Figueroa Yánez ha escrito lo siguiente: "la nave, sus aparejos y sus fletes no devengados constituyen un patrimonio separado o especial, de afectación, destinado a realizar los actos de comercio marítimo que demande la actividad naviera. Se ha llamado a este patrimonio marítimo 'fortuna de mar', para distinguirlo del patrimonio o 'fortuna de tierra' del naviero, el cual está formado por el resto de sus bienes. El naviero tiene, así, dos patrimonios o 'fortunas' separadas: la de tierra y la de mar,

${ }^{6}$ Ripert, Georges, Compendio de Derecho Maritimo (Traducción de Pedro G. San Martín, Buenos Aires, 1954), p. 132.

${ }^{7}$ Fariña, Francisco, Derecho Comercial Marítimo (Barcelona, 1955), I, p. 151. 
constituidas por bienes y deudas diferentes entre sí"

La ratio legis que subyace bajo esta noción es que, tratándose la navegación marítima de una actividad de suyo riesgosa, el armador que se aventuraba a explotarla comercialmente sólo arriesgaba la nave que hacía a la mar, pero no sus restantes bienes que permanecían en tierra. Curiosamente, aquí confluyen las dos acepciones de la "fortuna de mar", porque hemos de tener en mente que en el derecho marítimo, la expresión fortuna de mar también tiene una acepción que podríamos asimilar a los peligros de la navegación (perils of the sea), que se refiere a los riesgos que pueden producirse durante la navegación marítima. Como afirma García Infante: "La aventura marítima no sólo está sujeta a las venturas de la mar sino que también a otros riesgos potenciales. En todo este contexto aparecen los naufragios, los temporales, los abordajes, los robos, los incendios, los accidentes del trabajo, las huelgas, sólo por citar algunos. A su vez ellos dicen relación con la nave, con su dotación o con la carga que se transporta, revistiendo los riesgos la calidad de personales, reales o patrimoniales, pudiendo provenir de peligros propios del buque, de hechos del hombre, de la naturaleza, de la carga, etc. A tales riesgos se les denomina genéricamente 'fortuna de mar'"

Digo que es curioso porque este concepto de fortuna de mar, esencialmente náutico, se adentra en la propia esencia de la navegación marítima, en que el riesgo o peligro es una nota característica e inherente, que precisamente explica y justifica la noción jurídica de fortuna de mar (o patrimonio naval, para evitar confusiones): es la fortuna de mar, el peligro que la navegación conlleva, lo que lleva al legislador a concebir la afectación de un patrimonio especial e independiente para su explotación, separado de los restantes bienes de su titular, para circunscribir y limitar a ella el riesgo de esta actividad.

Así, la fortuna de mar da paso al patrimonio naval, como una manera de circunscribir la responsabilidad o exposición del armador que se aventura a la navegación marítima. Nos encontramos aquí con el concepto de limitación de responsabilidad, y ya señalábamos que el patrimonio naval era un vehículo a través del cual se regulaba la limitación de responsabilidad.

García Infante relaciona a la responsabilidad limitada del armador, propia del tráfico marítimo: "con su imprevisible y, por ende a priori, incalculable factor de riesgo, que se traduce en un concepto patrimonial que se conoció como 'fortuna de mar', que no sólo pasa a ser constitutivo

\footnotetext{
${ }^{8}$ Figueroa Yánez, Gonzalo, El Patrimonio (Santiago, 1991), p. 109.

${ }^{9}$ García Infante, Félix, Derecho del Transporte Marítimo, Comentarios, Legislación Comercial y Administrativa (Valparaíso, 1993), p. 385.
} 
de un patrimonio separado del restante que posea el armador, sino que se limita a la nave que afecta el hecho originador de la responsabilidad, incrementado en los fletes percibidos o por percibir en razón del viaje a que esos hechos y obligaciones se refieran" ${ }^{\prime \prime}$.

\section{El abandono de la nave en el antiguo libro III.}

El artículo 879 de nuestro antiguo libro III del Código de Comercio rezaba: "El naviero, sea o no propietario de la nave, podrá libertarse de responder de los hechos del capitán y tripulación y de las obligaciones contraidas por aquel, abandonando la nave y los fletes percibidos o por percibir en razón del viaje a que esos hechos y obligaciones se refieran". El abandono de la nave, que provenía del Código de Comercio francés y, a su vez, de la Ordenanza de Marina de 1681, otorgaba a los acreedores del naviero el derecho a hacer realizar la nave, para pagarse con el producto del remate, en el orden que establecían sus privilegios. Si el producto excedía a las deudas, el remanente se le restituía al naviero, mientras que si no alcanzaba para pagarlas, en aquellos saldos insolutos, se extinguían los créditos, y es aquí donde operaba el efecto limitativo de responsabilidad del abandono. El abandono no transfería el dominio de la nave a los acreedores (no era una dación en pago), sino que se asemejaba más a una cesión de bienes, puesto que les confería el derecho a realizarla y pagarse con el producido, y por ello se le llamaba abandono subasta.

Contreras Strauch sintetiza la relación entre fortuna de mar y abandono en las siguientes palabras: "Así nace el concepto de 'fortuna de mar', constituido por un patrimonio especial del naviero formado por la nave y los fletes. La 'fortuna de mar' dio origen a la institución que se conoce en la doctrina con el nombre de 'abandono liberatorio' y que estaba regulada en los artículos 879 y siguientes del primitivo libro III del Código de Comercio, hoy derogado" $"$.

Resaltemos dos notas características del abandono, en cuanto sistema de limitación de responsabilidad. Primero, en este sistema, la limitación de responsabilidad funcionaba como una limitación de la masa patrimonial, vale decir, que el armador respondía sólo hasta el valor que tuvieran los componentes activos de esa masa (representados principalmente por la nave), que se reflejaba en el producto de la realización. Esto, a diferencia de otros sistemas de limitación de responsabilidad, en que se limita el quantum de la deuda, prescindiendo de los bienes en que ella puede hacerse efectiva, como sucede en los sistemas tarifarios.

\footnotetext{
${ }^{10}$ García Infante, cit., p. 184.

${ }^{11}$ Contreras Strauch, Osvaldo, Derecho Maritimo (Santiago, 2000), p. 317.
} 
Una segunda nota es que en nuestro antiguo abandono, la fortuna de mar se liquidaba al valor que la nave y los demás activos tuvieran al término de la expedición marítima, lo que se criticaba, puesto que si la nave se hundía o se destruía, su valor de realización podía ser muy exiguo (o simplemente no rematarse por falta de interesados, como sucedía con los restos náufragos), y los acreedores se quedaban sin ser pagados de sus créditos. No sucede así en el sistema alemán, donde la fortuna de mar (seevermogen) se conformaba al inicio de la expedición, de manera que el monto al que ascendía la limitación se congelaba antes que la nave sufriera los embates propios de la aventura marítima. En otras palabras, los riesgos de la expedición permanecían en el armador y no se transferían a sus acreedores. Mientras nuestro abandono era un patrimonio de liquidación, en este otro sistema funciona como un patrimonio de explotación.

\section{El actual sistema de limitación de responsabilidad.}

Las normas que establecen límites de responsabilidad en nuestro actual Derecho Marítimo son el artículo 895 (que consagra el tarifado del sistema general de limitación de responsabilidad del armador y otros sujetos de la navegación marítima); los artículos 992 y 993 (que establecen los límites de responsabilidad del porteador marítimo) y los artículos 1063, 1065 y 1066 (que determinan los límites de responsabilidad del transportador de pasajeros), todas normas del Código de Comercio. Por su parte, el artículo 145 del Decreto Ley 2.222, de 1978 (Ley de Navegación), consagra la limitación de responsabilidad por derrame de materias o desechos.

Todas estas normas tienen un denominador común: consagran un sistema tarifario de limitación de responsabilidad, en que el quantum al que se restringirá la obligación del armador u otro sujeto (que en general es una obligación indemnizatoria por un accidente de la navegación o el incumplimiento de un contrato marítimo) se determina en una suma fijada por la ley con anterioridad a que suceda el evento que origina esa responsabilidad. Esta suma puede establecerse en función del tonelaje de arqueo o registro de la nave (como sucede en el sistema general de limitación del libro III y en el sistema de limitación por derrames de la Ley de Navegación), o en función de la cantidad de bultos transportados o su peso (como es el caso del transporte de mercancías) o en una suma determinada por pasajero (como sucede en el contrato de pasaje). Pero, a diferencia de la limitación de responsabilidad en base a una masa, no se establecen los bienes o activos con los cuales el deudor garantiza y eventualmente habrá de pagar y hacer frente a tales deudas. A diferencia del abandono, en que se reserva un patrimonio para los acreedores, en este sistema se limita el crédito, pero no hay un aislamiento de la masa en que ellos se satisfarán. 
Entonces, en teoría, el acreedor podría dirigirse en contra de cualquier bien del deudor para hacerse pago de su crédito, aún limitadamente.

\section{El fondo de limitación de responsabilidad.}

He señalado que, en "teoría”, el acreedor podría dirigirse contra cualquier bien del deudor, porque aquí nos topamos con dos figuras: el crédito privilegiado y el fondo de limitación de responsabilidad. En estas figuras se reúnen las nociones de patrimonio naval y de limitación de responsabilidad.

Tratándose del privilegio marítimo, el acreedor privilegiado sólo podrá hacer uso de las atribuciones que este privilegio le confiere (derecho de persecución, realización y pago preferente) en contra de la nave y de los demás activos de la fortuna de mar. Así lo dispone el artículo 842: "Los privilegios de que trata este párrafo, otorgan al acreedor el derecho de perseguir la nave en poder de quien se halle y hacerse pagar con su producto preferentemente a los demás acreedores, según el orden aqui establecido”. Esto ya importa una restricción, porque el legislador ha separado el patrimonio naval para satisfacer ciertas deudas que ha elevado a la categoría de créditos privilegiados. Dicho a la inversa, el privilegio marítimo no alcanza a los bienes del patrimonio terrestre del propietario o armador de la nave.

La segunda figura es el fondo de limitación de responsabilidad. Regulado en el párrafo 4 del título $4^{\circ}$ del libro III, rubricado: Del procedimiento para la constitución y distribución del fondo de limitación de responsabilidad, comienza con el artículo 1210, que señala: "Cualquiera de las personas mencionadas en el párrafo 1 del título IVy en el párrafo 3 del titulo $V$ de este Libro ${ }^{12}$, que se considere con derecho a limitar responsabilidad, o el asegurador en su caso, podrá ocurrir ante alguno de los tribunales que se indican en el articulo siguiente, y solicitar que se inicie un procedimiento con el objeto de constituir el fondo, verificar y liquidar los créditos, y para efectuar su repartimiento de acuerdo con las normas de prelación que disponga la ley".

Una norma similar encontramos en el artículo 145, número 1 de la Ley de Navegación, que reza: "El que pretende gozar de la limitación deberá constituir ante el tribunal que establece este titulo ante el que pudiere ser también competente según el Convenio, un fondo cuya cuantía ascienda al limite de responsabilidad dispuesto en este articulo".

La interrelación entre ambos fondos se regula en el artículo 897, que

\footnotetext{
${ }^{12}$ Nótese que no se mencionan las normas del contrato de pasaje en que también existe el derecho a limitar responsabilidad, lo que abre la interrogante si a esa limitación se aplica o no éste procedimiento para constituir y distribuir el fondo de limitación de responsabilidad, ¿omisión deliberada o involuntaria del legislador...?
} 
dispone: "Cuando unos mismos hechos produjeren responsabilidades para el armador, respecto de los cuales le asista el derecho a limitación, según las normas de este Libro y, además, esos mismos hechos produjeren responsabilidades por las cuales el armador también tiene el derecho a limitar responsabilidad, conforme a las normas del titulo IX de la Ley de Navegación, y resolviere hacer uso de estos derechos, deberá constituir el número de fondos independientes que corresponda, de manera que ni los fondos ni los créditos se confundan entre si".

Aquí convergen un derecho sustantivo, que es el de limitar responsabilidad, con una institución procesal, cual es el fondo de limitación de responsabilidad, y el requisito o carga que la ley coloca a quien quiera gozar de la limitación es constituir un fondo e iniciar el procedimiento de limitación. Se permite constituir el fondo en dinero o por medio de una garantía ${ }^{13}$, y el sentido de esta exigencia es condicionar el beneficio de la limitación de responsabilidad a que el deudor destine una suma de dinero (o una garantía) precisamente para hacer frente a los créditos a los que opondrá la limitación de responsabilidad.

Esta exigencia merece tres comentarios. Primero, desde el punto de vista procesal, se busca compensar al acreedor a quien se le limita su crédito con alivianarle la tarea de buscar y perseguir bienes en los cuales hacerse pago del mismo. He aquí un quid pro quo: se restringe cuantitativamente la posibilidad de indemnización, pero se le compensa con destinar bienes para servir a esa deuda. Segundo, nos encontramos ante un juego de la limitación de deuda o tarifaria con la limitación de masa o patrimonial, con el bemol que la limitación de masa se refiere a una suma de dinero

${ }^{13}$ Así fluye de los artículos 1213: "La petición sobre apertura del procedimiento deberá indicar: [...]. 3. La forma como se constituirá el fondo, sea en dinero o mediante garantía. El tribunal calificará la suficiencia de ella"; 1215: "El tribunal, luego de examinar si los cálculos del proponente sobre el monto del fondo, se ajustan a las disposiciones pertinentes del párrafo 1 del título IV o del párrafo 3 del título $V$ de este Libro, según corresponda, dictará un auto por el que declarará iniciado el procedimiento. Simultáneamente, se pronunciará sobre las modalidades ofrecidas para la constitución del fondo, ordenando su cumplimiento si las aprueba [...]"; 1216: "Cuando para la constitución del fondo se entregue dinero, el tribunal lo depositará en un banco, con conocimiento del sindico y de los interesados. Los reajustes e intereses que se obtengan incrementarán el fondo en beneficio de los acreedores. Si el fondo ha sido constituido mediante una garantía, su importe devengará los intereses corrientes en el lugar de asiento del tribunal, de lo que se dejará constancia en el documento constitutivo de la garantía"; 1217: "Constituido el fondo o aceptada la garantía sobre su constitución, el tribunal lo declarará asi [...]”. Por su parte, el artículo 145, $\mathrm{N}^{\circ} 1$ de la Ley de Navegación, señala: "El fondo podrá constituirse consignando la suma o depositando una garantía bancaria o de otra clase, considerada suficiente por el tribunal". 
(género por excelencia) y no a ciertos bienes, es decir, trasciende al patrimonio naval.

El tercer comentario apunta a la idea de balance o equilibrio que se ha concebido existe entre las figuras del patrimonio naval y de la limitación de responsabilidad, por cuanto se ha entendido, a lo largo de la evolución del derecho marítimo, que a los acreedores marítimos a quienes se les puede oponer el beneficio de la limitación de responsabilidad (que en la práctica importa cercenarle sus créditos) se los compensa reservándoles una masa de bienes en los cuales pueden hacerse un pago preferente de los mismos, por sobre los demás acreedores terrestres. Como señala el Informe Técnico de la Comisión que redactó el Proyecto de libro III (de 10 de diciembre de 1985): "se ha estructurado el derecho del naviero a limitar responsabilidad frente a sus acreedores-que antes se operaba por el abandono-mediante la entrega de un fondo" 4 . Y añade: "El derecho de limitación afecta precisamente a los acreedores del tráfico. Es de justicia entonces que estos, que pueden ser castigados en sus acreencias, tengan como contrapartida al menos el derecho de pago preferente aún respecto a acreedores ajenos a aquella actividad (a los cuales no se les puede oponer la limitación) para pagarse sobre la nave o el fondo de limitación que la reemplace. Resolver de otra manera, habría sido poner en peligro toda la confianza crediticia que se produce en torno a la actividad armatorial, con los privilegios maritimos y con el derecho de persecución"15.

El efecto de la carga de destinar una suma de dinero o una garantía para el pago de los créditos a los que se opone la limitación se plasma en el artículo 1217, que prescribe: "Constituido el fondo o aceptada la garantía sobre su constitución, el tribunal lo declarará así, y desde la fecha de esta resolución, se suspenderá toda ejecución individual o medida precautoria contra el requirente, respecto de los créditos a los cuales puede oponerse la limitación de responsabilidad. No se podrá impetrar derecho alguno sobre el fondo, el cual queda exclusivamente destinado al pago de los créditos respecto de los cuales se puede oponer la limitación de responsabilidad".

Esta norma contiene dos aspectos importantes. El primero se refiere a que la constitución del fondo de limitación hace cesar todas las ejecuciones individuales, e incluso las medidas precautorias (expresión que incluye al arraigo de una nave, que es una medida precautoria especial), lo que es propio de un procedimiento concursal, como éste, cuyo objeto es reunir todas las ejecuciones en un mismo proceso, a objeto de hacer una única repartición del patrimonio ejecutado entre los acreedores, lo que necesariamente conlleva la terminación de las ejecuciones individuales que se

\footnotetext{
${ }^{14}$ Informe Técnico de la Comisión Redactora del Libro Tercero, cit., p. 9.

${ }^{15}$ Informe Técnico de la Comisión Redactora del Libro Tercero, cit., p. 9.
} 
hayan efectuado fuera de este proceso.

El segundo aspecto consiste en lo que se denomina el "congelamiento" del fondo, el que permanece intangible para los restantes acreedores que no son parte de este proceso, sino que destinado exclusivamente al pago de las deudas a las que se opone la limitación de responsabilidad. El fondo se reserva para el servicio de estas deudas.

Ambos aspectos se explican en la noción de patrimonio naval, ya que en la medida que se destina una masa para el pago a los acreedores marítimos, garantizándoles que los restantes acreedores no tendrán acceso a ella, a cambio de impedírsele a estos mismos acreedores proseguir o iniciar procesos individuales de cobro de sus créditos, lo que se hace es concretar procesalmente este patrimonio naval, el que se separa y aísla para el servicio de estos determinados créditos.

El lector podría cuestionar el raciocinio diciendo, ¿pero el fondo así constituido no es la nave, en consecuencia, de qué fortuna de mar estamos hablando? La respuesta a este punto es: efectivamente no es la fortuna de mar, pero al constituirse el fondo se suspenden las ejecuciones individuales, medidas precautorias y arraigos. De esta forma, el acreedor privilegiado puede asegurar el pago de su crédito mediante el arraigo de la nave objeto del mismo [o de una nave hermana o emparentada, en los casos del artículo 1234 letra b)], y si el deudor constituye el fondo, este reemplazará a la nave como objeto de la ejecución, haciendo cesar el arraigo y las ejecuciones individuales, pero conservando el acreedor el rango que su privilegio le confiere. Y, por esta vía, la noción de fortuna de mar, en cuanto patrimonio separado para los acreedores marítimos, se mantiene.

En este sentido, la función del fondo es doble. Respecto del acreedor, sin afectarle su crédito, se le confiere liquidez y se le libera de tener que proseguir en la ejecución individual, ya que se coloca dinero a su disposición para que pueda pagarse en él. Respecto de quien constituye el fondo, éste le permitirá seguir explotando la nave, que queda liberada por efecto de la norma antes analizada, lo que subsana una de las críticas del sistema del abandono, cual era que el naviero que quisiera gozar de los beneficios de la limitación debía abandonar la nave para hacer pago a sus acreedores, desprendiéndose de su capital de trabajo. El sistema del fondo permite, sin desmedro de los acreedores, que el deudor siga explotando el giro marítimo.

\section{NATURALEZA JURÍDICA DE LA FORTUNA DE MAR}

En general, existe consenso en que la fortuna de mar conforma un patrimonio naval que es distinto y separado de los bienes del armador en 
tierra. Pero, a la hora de establecer la naturaleza jurídica exacta de esta masa de bienes han existido distintas explicaciones.

\section{El patrimonio como atributo de la personalidad.}

La doctrina clásica de los franceses Aubry y Rau concebían al patrimonio como una emanación de la personalidad: "La persona constituye el soporte del patrimonio, el cual no puede existir sin ella"16, de suerte que las relaciones entre persona y patrimonio son: sólo las personas (naturales y jurídicas) pueden tener un patrimonio, pues sólo ellas tienen la facultad de adquirir derechos y contraer obligaciones; toda persona natural y jurídica tiene un patrimonio, aunque actualmente no posea bien alguno $\mathrm{y}$ una persona no puede tener sino un patrimonio.

Prescindiendo de las críticas que esta doctrina ha recibido desde los propios civilistas, analicemos si estos postulados son o no válidos respecto a la fortuna de mar. En aras de la claridad, discurriré en el orden inverso al que las expuse. Primero, que una persona no puede tener sino un patrimonio no es correcto, porque, de una parte, el propietario de una nave o su armador (no propietario) generalmente tienen un patrimonio en tierra antes de ingresar al negocio marítimo, de hecho, el capital que utilizan al efecto proviene de sus arcas terrestres y, de otro, cuando el negocio marítimo prospera y amplían su flota, constituyen una fortuna de mar separada por cada otra nave que explotan.

Segundo, que toda persona natural y jurídica tenga un patrimonio, aunque no posea bien alguno no es predicable de la fortuna de mar, porque el que no posee o explota una nave, jamás tendrá un patrimonio naval. De hecho, la generalidad de los seres humanos no posee un patrimonio naval.

$\mathrm{Y}$, tercero, que sólo las personas puedan tener un patrimonio tampoco es correcto, porque en el caso del patrimonio naval, podemos encontrar a un propietario no armador, un armador no dueńo, un operador, un fletante, un fletador, un transportador, etc., que participan de la explotación comercial de la misma nave, y todos ellos están administrando esa fortuna de mar y gravándola con privilegios marítimos, sin que todos ellos sean los dueños de la nave (algunos meros tenedores y otros ni siquiera tenedores), de manera que la figura personal pasa a un segundo plano y lo que resalta como el epicentro de la masa es la explotación comercial de la nave, que es un fin distinto a las personas que efectúan esta actividad. La titularidad

${ }^{16}$ Salvat, Tratado de Derecho Civil Argentino, Parte General (Buenos Aires, 1947), II, p. 7, citado por Luis Bustamante Salazar, El Patrimonio. Dogmática Jurídica (Santiago, 1979), p. 29. 
de la persona se desplaza por la titularidad del fin.

La doctrina tradicional no explica, pues, la noción de fortuna de mar.

\section{La teoría de la personificación de la nave.}

Otra teoría es la personificación de la nave, que lleva la separación de la fortuna de mar del patrimonio de tierra al extremo de otorgarle una verdadera personalidad a la nave, considerándola como acreedora de los derechos que le asisten, por ejemplo, el del flete por los servicios de navegación o transporte efectuados, o la remuneración en caso de salvamento y, a la inversa, como deudora ante sus tripulantes por los salarios y emolumentos de estos o ante la nave que haya abordado por el daño irrogado, por colocar un par de ejemplos. El tratadista belga Smeesters, citado por Francisco Fariña, sostiene que "no es el propietario, ni el armador, ni el fletador quienes causan el daño, es el buque; por tanto, es el buque, o más bien la aventura, quienes responden"17. A su vez, Thomas dice: "Bajo esta teoría el buque se personifica y se considera como una entidad jurídica con capacidad de contratar y cometer delitos civiles. La nave es la fuente y límite de la responsabilidad. Cuando un daño se causa por una nave, el buque en sí mismo es el 'ofensor' o 'malhechor' y se le condena por la culpabilidad"18. Explica Thomas que esta teoría tuvo su mayor impacto en el desarrollo del derecho marítimo de los Estados Unidos, aunque su influencia en la jurisprudencia contemporánea ha disminuido y en el derecho inglés tiene poca resonancia y, si bien se personifica a los buques en los fallos judiciales ${ }^{19}$, esto no significa ningún compromiso teórico, sino que una "técnica lingüística que facilita la exposición" 20 .

Según el Profesor norteamericano Robert Force: "bajo la doctrina de la personificación, la nave se considera responsable de sus ilícitos y obligaciones contractuales que se contraen por su cuenta para facilitar el cumplimiento de su misión"21. Cualquiera sea su origen, "la personificación de la nave ha tenido una carrera notable en las opiniones judiciales norte-

${ }^{17}$ FARIÑA, Francisco, cit., p. 138.

${ }^{18}$ D.R. Thomas, Maritime Liens, British Shipping Laws (London, 1980), IV, p. 7.

${ }^{19}$ Así, por ejemplo, al definir al maritime lien, que es la versión inglesa del privilegio marítimo, Gorell Barnes, en The Ripon City (1897), p. 226, 242, citado por D.R. Thomas, cit., p. 10, señaló que el lien es un reclamo privilegiado sobre una nave respecto de un servicio que se le ha brindado, o de un daño causado por ella, a ser llevado a efecto por medio de un proceso legal [...]".

${ }^{20}$ Thomas, cit., p. 7.

${ }^{21}$ Force, Robert, Admiralty and Maritime Law (Publicación del Federal Judicial Center, s. 1., 2004), p. 163. 
americanas y ha tenido, como las concepciones literarias a veces lo tienen, influencia en dar forma a la ley"22. En "The Little Charles", respecto de una nave que había sido confiscada por involucrarse en una violación a leyes de embargo, Chief Justice Marshall señaló “[...] este no es un proceso en contra del dueño, es un proceso en contra de la nave por una ofensa cometida por la nave, que no es sino una ofensa, y no hace sino hacerla sujeto de una confiscación, porque fue cometida sin la autoridad y contra la voluntad del dueño. Es verdad que las cosas inanimadas no pueden cometer ofensas. La madera, el hierro y las velas de la nave no pueden, por sí, violar la ley. Pero este cuerpo es animado y puesto en acción por la tripulación, que es guiada por el capitán. La nave actúa y habla por el capitán. Se reporta a sí misma por el capitán. En consecuencia, no es irrazonable, que la nave se vea afectada por tal reporte" ${ }^{23}$. En el caso Brig Malek Adhel, una nave requisada por acciones de piratería, la Corte Suprema decretó que "la nave que comete una agresión es tratada como la ofensora, como el instrumento culpable o la cosa afecta a la confiscación, sin referencia de ninguna especie a la persona o conducta de su dueño [...] y esto es hecho por la necesidad del caso, como el único medio adecuado para suprimir la ofensa o el mal, o asegurarle una indemnización a la parte damnificada" ${ }^{24}$.

Pero, no obstante haberse utilizado en fallos judiciales, "la ficción de la personalidad de la nave ha jugado un rol insignificante en el desarrollo del derecho de los privilegios marítimos. En sí, la cuestión se ha presentado en cada una de las recurrentes situaciones cuando ha existido un intento de ejercer un reclamo en contra de una nave por el cual, al momento de la demanda, su propietario no es responsable [...] si la teoría de la personificación estuviera en las raíces de nuestro derecho, tal conclusión se desprendería en cada caso que 'la nave' fuera responsable y el reclamo ejercible, lo que dista mucho de ser el resultado" 25 . Este autor remata diciendo que "puede concluirse que la ficción de la personalidad de la nave nunca ha sido algo más que un tema literario" 26 , y como tal adquirió popularidad al inicio del siglo, para luego decaer su reputación.

Este autor coloca una lápida sobre la teoría al comentar que "las ficciones sirven para muchos propósitos en el derecho. Inicialmente, su intro-

\footnotetext{
${ }^{22}$ Grant Gilmore - Charles L. Black Jr., The Law of Admiralty (2a edición, New York, 1975), p. 591.

${ }^{23} 26$ Fed. Cas. 979, Case No. 15,612 (C.C.D.Va. 1819), citado por GILmore - BLACK, cit., p. 591.

${ }^{24} 43$ U.S. (2 How.) 210, 233 (1844), citado por Gilmore - Black, cit., p. 593.

${ }^{25}$ Gilmore - Black, cit., p. 615.

${ }^{26}$ Gilmore - BlaCK, cit., p. 615.
} 
ducción es apta como un signo de disturbio y crecimiento. Pero cuando una ficción ya ha servido su tiempo y propósito, su desaparición, aunque sea aceptable e inocua como la ficción de la personalidad de la nave, es siempre bienvenida" 27 .

Pero no es el único en criticarla. Como apunta Scialoja: "la personificación del buque es tradicional y se remonta a una época en que realmente no podía ocultar ningún significado jurídico" 28 . Lo que sucede es que "ciertos autores llevaron tan adelante esta metáfora que llegaron a creer que se le podrían extraer deducciones jurídicas, y luego otros sostuvieron expresamente que el buque es, o debería ser, considerado como un sujeto jurídico" 29 , tesis que rebate por insostenible, agregando que para efectos del principio de la responsabilidad limitada a cuanto constituye el buque, "principio que conduce simplemente a considerar el buque como un patrimonio separado (universalidad de derecho) ya que, cuando se habla de limitación de responsabilidad se hace referencia siempre a la persona del propietario y armador, no al buque como sujeto" ${ }^{30}$. Scialoja sostiene que "el buque es considerado en derecho como una cosa, es decir, como un objeto de relaciones jurídicas, no como un sujeto"31. Agrega que "un conjunto de cosas o derechos adquiere diferente aspecto jurídico según el grado de organización que exista entre las varias cosas que lo constituyen"32, a esto lo califica como una universalidad de hecho y señala que éste es el caso del buque. Luego va más allá, agregando que "cuando de la unión de cosas determinadas la ley hace depender determinadas consecuencias jurídicas, más o menos amplias, hay universalidad de derecho. También este es el caso del buque en algunas situaciones, como en el abandono"33. Termina sentenciando "pero una mera universalidad de hecho o de derecho no puede considerarse como persona jurídica" 34 .

Más allá de lo ilustrativa, la cabida de esta teoría en nuestra legislación no resiste análisis, puesto que el artículo 827 es categórico en caracterizar a la nave como un bien mueble, que por tanto no puede ser sujeto de derechos ni de obligaciones. Así, desde un punto de vista sustantivo, la

${ }^{27}$ Gilmore - Black, cit., p. 616.

${ }^{28}$ Antonio Scialoja, Sistema del Derecho de la Navegación (1933, trad. castellana de Delia Viterbo de Frieder y Santiago Sentís Melendo, Buenos Aires, 1950), p. 201.

\footnotetext{
${ }^{29}$ Scialoja, cit., p. 202.

${ }^{30}$ Scialoja, cit., p. 202.

${ }^{31}$ Scialoja, cit., p. 201.

${ }^{32}$ Scialoja, cit., p. 202.

${ }^{33}$ Scialoja, cit., p. 202.

${ }^{34}$ Scialoja, cit., p. 203.
} 
teoría de la personificación de la nave no calza con nuestro ordenamiento marítimo.

Esta concepción de la nave como un sujeto se relaciona a las denominadas acciones in rem que existen en el Common Law, que son parecidas a nuestros derechos reales, en cuanto permiten dirigirse contra una cosa, sin respecto a determinada persona. Pero la actio in rem va más allá que nuestro derecho real, llegando a la "ficción legal de convertir a una cosa en el sujeto pasivo de una acción judicial" 35 . Podríamos decir que la teoría de la personificación de la nave se lleva hasta un plano procesal donde a la nave se la transforma prácticamente en un litigante. A este respecto, consta en la historia de nuestra ley que en el seno de la Comisión Revisora del Proyecto del Libro Tercero se optó por no introducir el sistema de las acciones in rem a nuestro derecho, ya que ello hubiera sido "ir un poco lejos", ya que "para la etapa de la evolución de nuestro derecho marítimo era todavía un poco prematuro crearlo", por lo que se mantuvo "el derecho de persecución, que tiene todo acreedor privilegiado sobre la nave y que estaba ya legislado en el antiguo código' ${ }^{136}$.

A mi juicio, se trató de una decisión consecuente y coherente. Consecuente, porque si a la nave se la considera una cosa mueble, desde un punto de vista sustantivo, mal podría tratársela como un sujeto de derecho en la esfera procesal. Y coherente, porque en Chile, aún en las acciones reales, el sujeto pasivo de ellas es siempre una persona, no una cosa. Piénsese en el caso de la acción reivindicatoria, que es la acción real por excelencia, ella se ejerce contra una persona que es el poseedor no dueño. Insertar la actio in rem habría, a mi juicio, creado una distorsión jurídica y judicial mayor, produciendo una serie de alteraciones procesales que los tribunales no estaban en posición de resolver, en suma, confundiendo el derecho.

Procesalmente, la teoría de la personificación de la nave (mediante la actio in rem) tampoco coincide con nuestro ordenamiento marítimo.

\section{La fortuna de mar como un patrimonio de afectación.}

En el sistema chileno, podemos caracterizar a la nave como una cosa conexa (res conexa) o compleja, que es una agregación de dos o más cosas singulares, al ser la nave formada por la reunión de varias partes o cosas (casco, maquinarias, pertenencias, etc.) que están unidas y que forman una cosa distinta de cada de una de las cosas singulares que la componen. Al respecto, el artículo 827 señala: "El concepto de nave comprende tanto el casco

${ }^{35}$ Cornejo Fuller, cit., p. 93.

${ }^{36}$ Citas de las Actas de la Comisión Revisora, correspondientes a la Sesión $\mathrm{N}^{\circ} 1$, de fecha 27 de agosto de 1986, p. 5; Sesión № 17, de fecha 31 de diciembre de 1986, p. 6; y Sesión $N^{\circ} 29$, de fecha 5 de mayo de 1987, p. 6. 
como la maquinaria y las pertenencias fijas o movibles que la complementan. No incluye el armamento, las vituallas ni fletes devengados". La nave puede concebirse, además, como una universalidad de hecho, al estar constituida por una reunión de varias cosas simples o complejas que están juntas por un fin común que es navegar.

Pero también podemos concebir a la nave, o más precisamente a la fortuna de mar que se erige en torno a su explotación como una universalidad de derecho, entendida como un conjunto de relaciones jurídicas constituida sobre una masa de bienes y reguladas como un todo jurídico. La fortuna de mar es una universalidad jurídica porque consiste en un conjunto de relaciones económicas y jurídicas que se generan con ocasión de la explotación comercial de la nave, que incluye activos (la nave, los fletes y las indemnizaciones) y pasivos (los privilegios marítimos) y esta universalidad de derecho es independiente de los derechos personales que el acreedor tenga en contra la persona que está operando o explotando la nave.

A mi juicio, la naturaleza jurídica de la fortuna de mar se explica en la figura del patrimonio de afectación. Según Bernardo Windscheid: "existen derechos, los cuales no se encuentran ligados a un hombre como sujeto. De donde se deduce que existen derechos que tienen por destino servir a cierto fin" ${ }^{37}$. Planiol y Ripert opinan que: "lo que crea la cohesión entre los elementos de las universalidades de que se trata es la afectación de dichos elementos a un destino particular común y no la personalidad del titular"38. Citando a Fadda y Bensa, agregan: "la suma de bienes pertenecientes a una persona no queda por este solo hecho constituida en unidad; pero puede ocurrir que la ley, con determinadas miras, lo haga. El punto decisivo es éste: que la unificación de los elementos se concrete a un fin querido por la ley" ${ }^{39}$. La noción de patrimonio de afectación se construye sobre la base de destinar bienes y deudas en torno a un mismo fin, independiente de las personas que los posean o administren. Son "patrimonios objetivos, sin vinculación con persona alguna, consistentes en una agrupación de bienes y de deudas apreciables en dinero, con valor pecuniario, en torno a un fin común, en que la existencia o no de una persona no tenía importancia alguna" 40 .

$\mathrm{Al}$ referirse a la nave, Figueroa Yánez califica a la fortuna de mar como

\footnotetext{
${ }^{37}$ Bustamante Salazar, op. cit., p. 32.

${ }^{38}$ Planiol - Ripert, Traite practique de Droit Civil Français (Paris, 1926), III, p. 25, citado por Bustamante Salazar, cit, p. 34.

${ }^{39}$ Fadda - Bensa, Notas a la traducción italiana del "Diritto delle Pandette" de Windscheid (Turín, 1925), iv, p. 192, citado por Bustamante Salazar, cit., p. 34.

${ }^{40}$ Figueroa Yáñez, cit., p. 40.
} 
un "verdadero patrimonio de afectación destinado a realizar los actos de comercio marítimo que demanda la actividad naviera" ${ }^{41}$. Añade: "lo que interesa recalcar aquí es la posición de nuestro Código de Comercio, que claramente se inclina a favor de la doctrina objetiva o finalista del patrimonio, al aceptar que un mismo titular lo sea de diversos patrimonios diferentes entre sí, con sus bienes y deudas específicas" ${ }^{2}$. Concluye que "el sistema del Código de Comercio chileno tiene sus raíces en el Derecho Comercial medieval, en el cual ese sistema fue ideado para excluir los bienes personales del naviero, su 'fortuna de tierra', de los riesgos de la navegación, que entonces era una actividad azarosa y aleatoria. El sistema fue luego recogido por los principales Códigos de Comercio y leyes comerciales europeos y de ahí pasó a nuestro Código de Comercio" ${ }^{3}$.

La noción de fortuna de mar coincide con el de patrimonio de afectación, en que la nave, el flete y las demás indemnizaciones y créditos que forman sus activos giran en torno a un fin común que los agrupa: la explotación comercial de la navegación y transporte marítimos. En cuanto activos, sirven a los créditos privilegiados, dotándose a sus acreedores de la facultad de perseguir su pago en la nave (por medio del procedimiento judicial denominado arraigo), la que pueden realizar, y con el producto de su realización proceder al pago en el orden y rango que la misma ley establece. La constitución del fondo de limitación de responsabilidad reemplaza a la nave en cuanto objeto del privilegio, liberándola y permitiendo al naviero continuar con su explotación.

La objetividad del patrimonio que conforma la fortuna de mar se corrobora en cuanto no se requiere que sea el propietario quien pueda gravarla con privilegios marítimos. Por el contrario, el armador, el operador, el transportador, el fletante o el fletador también pueden gravarla con privilegios marítimos. Ambas ideas sólo son posibles si se entiende que el epicentro de este patrimonio es la explotación comercial de la nave en el negocio marítimo, de suerte que la persona de su propietario pasa a un segundo plano, y el patrimonio se erige sobre la actividad.

\section{CONCLUSIÓN}

A mi juicio, la respuesta a la pregunta con que he titulado este artículo es afirmativa, ya que la ley separa una masa de bienes y derechos de importante entidad económica, que afecta a un fin (la explotación en el negocio marítimo) y destina al servicio preferente de ciertas deudas, cuyos

\footnotetext{
${ }^{41}$ Figueroa Yáñez, cit., p. 532.

${ }^{42}$ Figueroa YáŃEZ, cit., p. 534.

${ }^{43}$ Figueroa YÁŃEZ, cit., p. 534.
} 
acreedores (marítimos) son dotados del derecho de perseguir tales bienes, arraigarlos, realizarlos y pagarse de acuerdo a su orden de prelación por sobre los acreedores terrestres. Luego, si el titular de este patrimonio (que puede ser el dueño de la nave o su armador no propietario), desea liberarla de estos gravámenes, puede hacer uso del derecho a limitar su responsabilidad, constituir un fondo de limitación y recuperar la libre disposición de su fortuna de mar.

$\mathrm{Si}$ bien el legislador no denomina expresamente a esta masa como patrimonio naval o fortuna de mar, sí regula los principales elementos que compone un patrimonio: activos, pasivos, disposición y prelación del pago de las deudas que lo gravan. También está delineada su relación con otras instituciones que son relacionadas y cercanas, como los privilegios marítimos, el arraigo de naves, la limitación de responsabilidad y el fondo de limitación. Más aún, constan en la historia de la ley cual fue el objetivo del legislador al regular esta materia y lo que tuvo en mente al darle su configuración elegida. Tras esto, existe un importante aporte doctrinario, nacional y extranjero, que coincide acerca de la concepción y la naturaleza de la figura, por lo que fundadamente podría decirse que se trata de conceptos jurídicamente decantados.

[Recibido el 27 de septiembre y aceptado el 19 de octubre de 2007].

\section{BIBLIOGRAFÍA}

Actas de la Comisión Revisora.

Barnes, Gorell, The Ripon City (1897).

Bustamante Salazar, Luis, El Patrimonio. Dogmática Jurídica (Santiago, 1979).

Contreras Strauch, Osvaldo, Derecho Marítimo (Santiago, 2000).

Cornejo Fuller, Eugenio, Derecho Marítimo Chileno. Explicaciones sobre el libro III del

Código de Comercio: De la Navegación y Comercio Marítimos (Valparaíso, 2003).

Fadda - Bensa, Notas a la traducción italiana del "Diritto delle Pandette" de Windscheid

(Turín, 1925), rv.

Fariña, Francisco, Derecho Comercial Marítimo (Barcelona, 1955), I.

Figueroa Yáñez, Gonzalo, El Patrimonio (Santiago, 1991)..

ForCe, Robert, Admiralty and Maritime Law (Publicación del Federal Judicial Center, s. 1., 2004).

García Infante, Félix, Derecho del Transporte Marítimo, Comentarios, Legislación Comercial y Administrativa (Valparaíso, 1993).

Gilmore, Grant - Black , Charles L., Jr., The Law of Admiralty (2a edición, New York, 1975).

Informe Técnico de la Comisión Redactora del Libro Tercero, de fecha 10 de diciembre de 1985. 
Planiol - Ripert, Traite practique de Droit Civil Français (Paris, 1926), III.

Ripert, Georges, Compendio de Derecho Maritimo (Traducción de Pedro G. San Martín, Buenos Aires, 1954).

Salvat, Tratado de Derecho Civil Argentino, Parte General (Buenos Aires, 1947), II. Scialoja, Antonio, Sistema del Derecho de la Navegación (1933, trad. castellana de Delia Viterbo de Frieder y Santiago Sentís Melendo, Buenos Aires, 1950).

Thомаs, D.R., Maritime Liens, British Shipping Laws (London, 1980), IV. 
